\title{
Benign lymphadenopathies
}

\author{
Lawrence M Weiss and Dennis O’Malley \\ Clarient Pathology Services, Inc., Aliso Viejo, CA, USA
}

\begin{abstract}
Benign lymphadenopathy is a common biopsy finding, and may often be confused with malignant lymphoma. It may be separated into major morphologic patterns, each with its own differential diagnosis with certain types of lymphoma. Most cases of reactive follicular hyperplasia is easy to diagnosis, but some cases may be confused with follicular lymphoma, but key morphologic, immunohistochemical, and molecular findings may usually distinguish between the two, particularly assessment of bcl-2 staining. Molecular studies to demonstrate B-cell clonality, as well as the $t(14 ; 18)$, may also be of great use in difficult cases. IgG4-associated sclerosing disease is discussed, as one recently described example of a specific type of reactive follicular hyperplasia in which the etiology may be suggested based on pathologic studies. While overlapping with the other types of hyperplasia, a high index of suspicion as well as IgG and IgG4 immunostains will help raise the possibility of the diagnosis that can be confirmed by further clinical studies. Reactive paracortical/interfollicular hyperplasia is another pattern of reactive hyperplasia, which may easily be confused with Hodgkin and non-Hodgkin lymphoma, particularly T-cell lymphoma. Epstein-Barr virus-associated infectious mononucleosis is an example of reactive paracortical/interfollicular hyperplasia, which may often simulate a malignant lymphoma. Attention to clinical findings, as well as a combination of immunohistochemical stains and in situ hybridization studies for EpsteinBarr early RNA (EBER) will usually allow a definitive diagnosis. In addition, lymph nodes with extensive necrosis may simulate malignant lymphoma. Kikuchi necrotizing histiocytic lymphadenitis is an example of a benign process with extensive necrosis, which may easily be confused with non-Hodgkin lymphoma. Clinical and morphologic features, particularly the presence of abundant karyorrhectic debris along with a paucity of granulocytes, as well as immunohistochemical studies to rule out lymphoma, are most helpful in establishing the correct diagnosis.
\end{abstract}

Modern Pathology (2013) 26, S88-S96; doi:10.1038/modpathol.2012.176

Keywords: acute infectious mononucleosis; atypical follicular hyperplasia; IgG4-related sclerosing diseaseassociated lymphadenopathy; Kikuchi histiocytic necrotizing lymphadenitis; reactive follicular hyperplasia; reactive interfollicular hyperplasia; reactive paracortical hyperplasia

All lymph nodes (unless an individual without any autoimmune or genetic disease, including cancer, lives under sterile conditions) are exposed to varying concentrations of different types of antigens. Thus, all non-neoplastic lymph nodes show varying degrees of reactive changes. These changes may be particularly marked in younger individuals, but may be observed in all ages. ${ }^{1-3}$ The most important consideration in assessing a reactive lymph node is in its distinction from a neoplasm, mainly the various types of malignant lymphoma. In a minority of circumstances, the specific pattern of reaction may strongly suggest a specific etiology. For these two reasons, it is helpful to try to characterize reactive lymphadenopathies by patterns of reaction. Each pattern suggests specific types of malignant lymphoma that may be considered in the differential

Correspondence: Dr LM Weiss, MD, Pathology, Clarient Pathology Services, Inc., 31 Columbia, Aliso Viejo, CA 92656, USA.

E-mail: lweiss@clarientinc.com

Received 16 July 2012; accepted 16 July 2012 diagnosis, and each pattern suggests a general type of immune response, which raises certain disease classes in the differential diagnosis. We have found it useful to separate benign lymphadenopathies into the following seven categories:

1. Follicular

2. Paracortical/interfollicular

3. Sinus

4. Extensive necrosis

5. Granulomatous

6. Connective tissue framework

7. Deposition of interstitial substance

One should also keep in mind that these patterns are never pure. Thus, reactive follicular hyperplasia usually has a component of paracortical hyperplasia, and sometimes one cannot even determine the dominant process. Nonetheless, from a differential diagnostic standpoint, it is useful to try to assess the dominant process. In this review, we will briefly review reactive follicular hyperplasia, with its differential diagnosis from follicular lymphoma, 
discussing IgG4-related sclerosing disease-associated lymphadenopathy as an example; reactive paracortical/interfollicular hyperplasia, discussing acute infectious mononucleosis as an example; and lymph nodes with extensive necrosis, discussing Kikuchi histiocytic necrotizing lymphadenitis as an example. Due to the limitations of this review, the other patterns will not be discussed.

\section{Reactive follicular hyperplasia}

Follicular hyperplasia is the most common pattern of reactive lymphadenopathy. It is usually associated with varying degrees of paracortical and/or sinus hyperplasia. It is particularly commonly seen in children and young adults, but may be encountered in all ages, including the very elderly. ${ }^{4}$ Clinically, the lymphadenopathy is usually localized, but may be generalized. The cervical and axillary areas are most frequently involved, corresponding to the lymph-node groups most likely to drain antigens. Table 1 lists the most common diseases that give rise to histologic findings that may suggest the specific etiology of the follicular hyperplasia.

\section{Atypical follicular hyperplasia}

Atypical follicular hyperplasia is a descriptive term that describes a diagnostic dilemma rather than a specific diagnosis. Table 2 lists the main histologic differential diagnostic features between reactive follicular hyperplasia and follicular lymphoma. ${ }^{5,6}$ Please note that there is no one pathognomonic histologic feature. Therefore, one should rather rely upon a constellation of characteristics. Even the history can be helpful. The older the patient, the more likely the diagnosis is follicular lymphoma. Generalized lymphadenopathy is also more commonly seen with follicular lymphoma than reactive follicular hyperplasia. The one single most useful histologic feature is the density of follicles (follicle:interfollicular ratio) on low magnification. The more the follicles and the less the interfollicular areas, the more likely is the diagnosis of malignant lymphoma. In fact, a complete back-to-back arrangement of the follicles is seen in over $75 \%$ of

Table 1 Specific reactive lymphadenopathies with a predominantly follicular pattern

- Rheumatoid arthritis

- Sjogren syndrome

- IgG4-related sclerosing disease

- Kimura disease

- Toxoplasmosis

- Syphilis

- Castleman disease

- HIV-associated lymphadenopathy

- Progressive transformation of germinal centers cases of follicular lymphoma, while only seen in the most florid cases of reactive follicular hyperplasia. The greatest exception to this rule is when there are areas of diffuse nodal effacement, another feature favoring follicular lymphoma. These areas are usually focal, but are mass forming, and not distributed evenly around individual follicles. Lymph nodes with floridly reactive follicles may also occasionally show one or more of the following features: extension of the process outside the capsule, the presence of follicles throughout the node, predominance of centroblasts, and absent or greatly diminished mantle zones (Figure 1). These latter two features are particularly common in florid reactive follicular hyperplasia occurring in childhood as well as in cases associated with human immunodeficiency virus infection.

Immunohistochemical and other special studies may be very helpful in distinguishing reactive follicular hyperplasia and follicular lymphoma. These studies are summarized in Table 3. Determination of bcl-2 expression in paraffin sections is the single most useful ancillary study, being consistently negative in reactive follicular hyperplasia, but positive in about $90 \%$ of cases of follicular lymphoma. ${ }^{7}$ However, one can occasionally see large numbers of bcl-2 + T-helper/inducer cells in cases of reactive follicular hyperplasia. ${ }^{7}$ Comparison with CD3 stains and the observation that the bcl$2+$ cells are not centroblasts can help with this pitfall. Another pitfall is to mistake bcl-2 + primary follicles for bcl-2 positivity in follicular lymphoma. Comparison with other stains, including a germinal center marker such as bcl-6 or CD10 or a marker of primary follicle lymphoid cells such as IgD may be helpful (Figure 2).

Table 2 Follicular hyperplasia vs lymphoma

\begin{tabular}{|c|c|}
\hline $\begin{array}{l}\text { Reactive follicular } \\
\text { hyperplasia }\end{array}$ & Follicular lymphoma \\
\hline Low density of follicles & High density of follicles \\
\hline $\begin{array}{l}\text { Follicles usually limited to } \\
\text { subcortical region }\end{array}$ & $\begin{array}{l}\text { Follicles distributed evenly } \\
\text { throughout nodal parenchyma }\end{array}$ \\
\hline $\begin{array}{l}\text { Follicles rarely extend } \\
\text { beyond capsule }\end{array}$ & $\begin{array}{l}\text { Follicles often extend beyond } \\
\text { capsule }\end{array}$ \\
\hline $\begin{array}{l}\text { Follicles of uneven size } \\
\text { and shape }\end{array}$ & $\begin{array}{l}\text { Follicles usually of similar } \\
\text { size and shape }\end{array}$ \\
\hline $\begin{array}{l}\text { Mixture of cell types in } \\
\text { germinal center }\end{array}$ & $\begin{array}{l}\text { Monomorphic or polymorphic } \\
\text { population }\end{array}$ \\
\hline $\begin{array}{l}\text { Tingible-body macrophages } \\
\text { present }\end{array}$ & $\begin{array}{l}\text { Tingible-body macrophages } \\
\text { usually rare }\end{array}$ \\
\hline $\begin{array}{l}\text { Usually moderate to high } \\
\text { mitotic rate }\end{array}$ & $\begin{array}{l}\text { Usually low to moderate mitotic } \\
\text { rate }\end{array}$ \\
\hline $\begin{array}{l}\text { Mantle zone usually } \\
\text { distinct }\end{array}$ & $\begin{array}{l}\text { Mantle zone usually indistinct } \\
\text { or absent }\end{array}$ \\
\hline Cell polarization often seen & Cell polarization usually absent \\
\hline $\begin{array}{l}\text { Large interfollicular areas } \\
\text { evident }\end{array}$ & Compressed interfollicular areas \\
\hline $\begin{array}{l}\text { Areas of nodal effacement } \\
\text { not seen }\end{array}$ & $\begin{array}{l}\text { May contain areas of nodal } \\
\text { effacement }\end{array}$ \\
\hline
\end{tabular}

Reactive follicular

Low density of follicles

Follicles usually limited to

subcortical region

Follicles of uneven size and shape

Mixture of cell types in

Tingible-body macrophages present

mitotic rat

distinct

evident

not seen
High density of follicles

icles distributed eventy Follicles often extend beyond capsule Monomorphic or polymorphic population

usually rare rate

Mantle zone usually indistinct or absent

Cell polarization usually absent effacement 


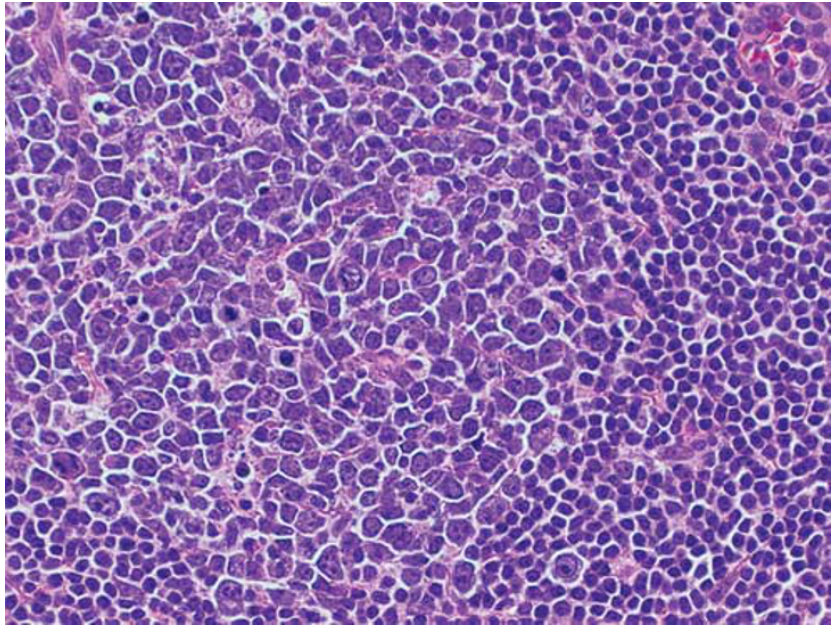

Figure 1 Reactive follicular hyperplasia. This germinal center has a predominance of large cells along with scattered tingible-body macrophages. Cases of reactive follicular hyperplasia that feature many large cells in the germinal centers are easily mistaken for a grade 3 follicular lymphoma. Note the sharp demarcation of the mantle zone from the germinal center.

Table 3 Follicular hyperplasia vs lymphoma: special studies

Reactive follicular hyperplasia Follicular lymphoma

Bcl-2 negative in B cells of germinal centers

No light chain restriction on immunostains (rare exceptions) No light chain restriction on flow cytometry (rare exceptions)

Ig rearrangements absent (rare exceptions)

Cytogenetic abnormalities infrequent, but have been described; $\mathrm{t}(14 ; 18)$ absent (rare exceptions)

The types of follicular lymphoma that are most likely to be bcl-2 negative include grade 3 follicular lymphoma and follicular lymphoma arising in children. In situ involvement by follicular lymphoma may show only scattered bcl- $2+$ cells, but the bcl-2 expression in this process is usually much stronger than the adjacent bcl-2 staining of either T-helper/inducer cells or adjacent B-mantle cells. Ki-67 stains may also be useful; not only are higher numbers of germinal center cells usually positive in reactive follicular hyperplasia than follicular lymphoma, the stain may demonstrate a pattern of polarity that may not have been evident on routine light microscopy. ${ }^{8}$ Immunoglobulin protein studies are helpful in only a minority of cases, as is also the case for in situ hybridization studies for mRNA expression; however, they are often most helpful in grade 3 follicular lymphoma. ${ }^{9}$ Rarely, florid reactive follicular hyperplasia, particularly in younger individuals, may show light chain restriction, particularly in flow cytometry studies. ${ }^{10,11}$ These
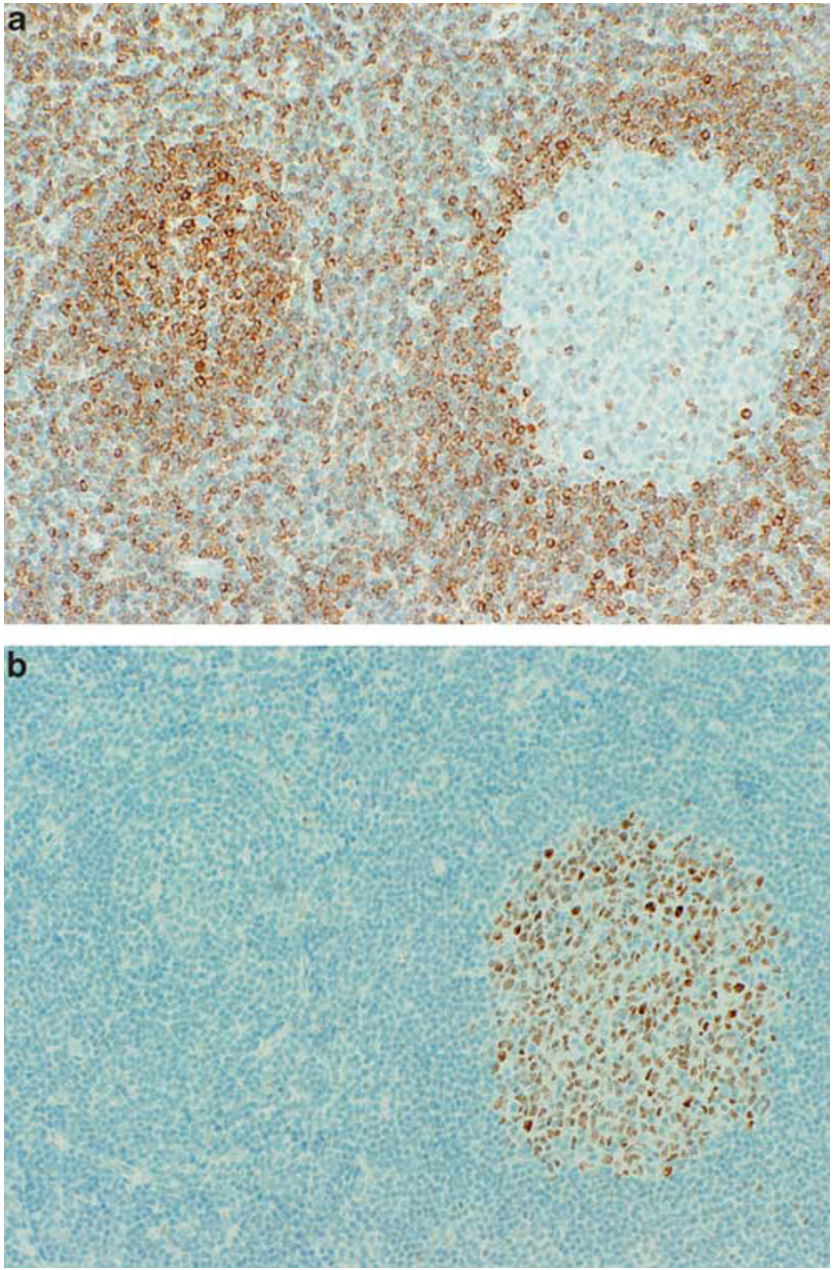

Figure 2 At left is a bcl-2 stain. The bcl-2-positive primary follicle may easily be mistaken for follicular lymphoma. At right is a serial section stained for bcl-6. The bcl-6 negativity is consistent with a primary folllicle.

cases are rare and may even show monoclonal populations by molecular analysis.

Gene rearrangement studies may be helpful in the distinction of reactive vs neoplastic follicular proliferations, although one must keep in mind that PCR studies for immunoglobulin heavy and light chains may be falsely negative in up to $20 \%$ of cases of follicular lymphoma due to the process of somatic hypermutation, and that 'pseudoclonal' immunoglobulin gene rearrangements may be rarely seen in reactive follicular hyperplasia, with the incidence depending on the primers used, the number of $\mathrm{B}$ cells in the specimen, as well as the size of the aliquot (particularly when $<50 \mathrm{ng}$ is analyzed). Similarly, although the detection of a $t(14 ; 18)$ (BCL2 gene rearrangement) usually provides strong support for a diagnosis of lymphoma, ${ }^{12}$ up to $10 \%$ of cases of follicular lymphoma (usually grade 3) may be negative, and the $\mathrm{t}(14 ; 18)$, as well as other cytogenetic abnormalities, may be rarely observed in reactive follicular hyperplasia. ${ }^{13}$ 


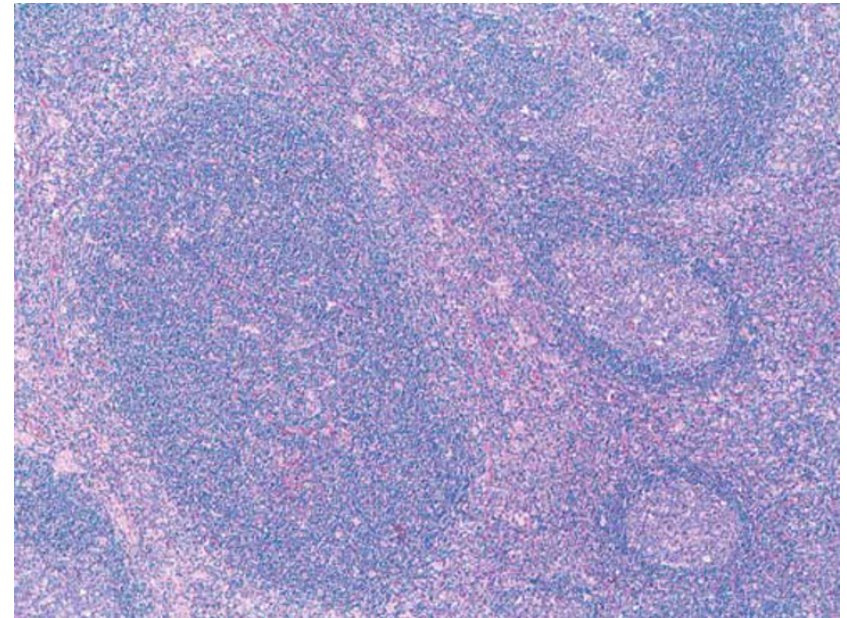

Figure 3 IgG4-related sclerosing disease. The larger follicle without the germinal center represents a progressively transformed germinal center. Progressively transformed germinal centers are enlarged follicles, with a proliferation of B-mantle cells in the nodule, sometimes breaking up the germinal centers. Note the clusters of epithelioid histiocytes at the margins.

\section{IgG4-related sclerosing disease- associated lymphadenopathy}

IgG4-related sclerosing disease is a recently recognized clinicopathologic syndrome, probably autoimmune in nature, characterized by tumor-like enlargement of one or more exocrine glands or extranodal sites, raised serum IgG4 levels, and a lymphoplasmacytic infiltration associated with sclerosis, with increased numbers of IgG4-secreting plasma cells. IgG4 is the least common subclass of IgG, constituting only about $3-6 \%$ of the entire IgG fraction. It is unique in its inability to bind C1q (and hence cannot activate the classical complement pathway). IgG4-related sclerosing disease involves numerous sites, particularly the pancreas (autoimmune pancreatitis/lymphoplasmacytic sclerosing pancreatitis), the biliary tract (lymphoplasmacytic cholecystitis; sclerosing cholangitis), submandibular gland (chronic sclerosing sialadenitis/Kuttner tumor), lacrimal gland (chronic sclerosing dacryoadenitis), liver ('inflammatory pseudotumor'), lung (interstitial pneumonia, 'inflammatory pseudotumor'), breast (IgG4-related sclerosing mastitis), kidney (tubulointerstitial nephritis; membranous glomerulopathy), soft tissues (retroperitoneal and mediastinal fibrosis), and other sites.

Lymph nodes may also be affected, and may show a predominantly follicular or paracortical pattern. ${ }^{14-16}$ Clinically, there is a marked male predominance in some series, affecting mostly middleaged to elderly individuals. The most common sites include mediastinal, intraabdominal, and axillary lymph nodes. Involved lymph nodes are usually not very large, commonly about $1-2 \mathrm{~cm}$. Exocrine and other extranodal lesions may precede, follow, or present together with the lymphadenopathy. Patients

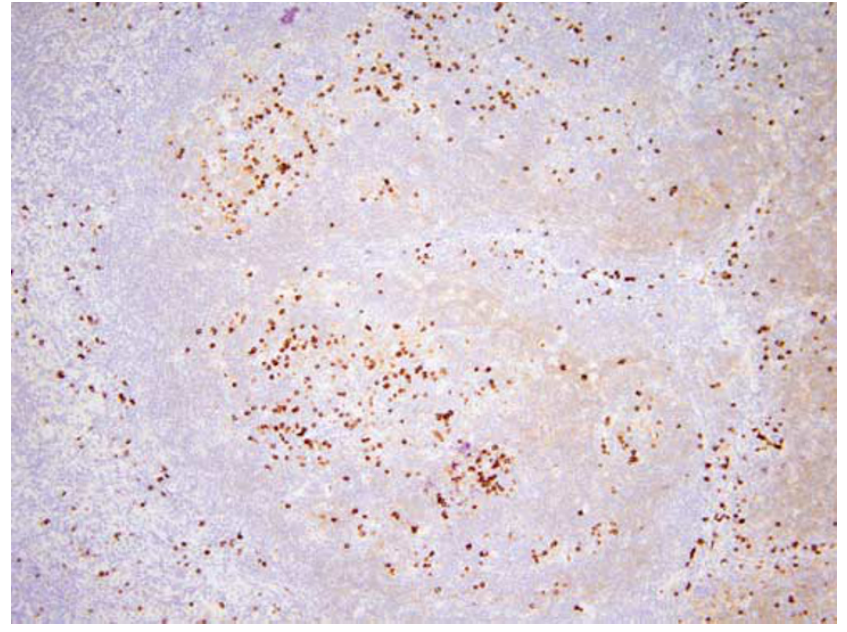

Figure 4 IgG4-related sclerosing disease, IgG4 stain. There is a marked increase in the number of IgG4-positive plasma cells, including many cells within germinal centers.

may have anemia (sometimes Coombs positive), increased ESR or C-reactive protein, elevated globulin and IgG levels, or the presence of autoantibodies, while LDH is normal or only slightly elevated. Morphologically, several patterns of involvement have been described. Some cases resemble the plasma cell/multicentric types of Castleman disease. In most cases, there is reactive follicular hyperplasia, often associated with an interfollicular plasmacytosis. Intrafollicular plasma cells may be seen in some cases, and progressive transformation of germinal centers, sometimes with a rim of epithelioid histiocytes, may be present in one-half of these cases (Figure 3). In a subset of cases, there is preferential paracortical expansion, always including plasma cells and sometimes having eosinophils. Focal areas of fibrosis may be present. The diagnosis may be confirmed by the identification of an elevated serum IgG4 level and increased numbers of IgG4 + plasma cells on immunostaining (IgG4 + cells $>50 / \mathrm{hpf}$ and an IgG4 $+/ \operatorname{IgG}+$ cell ratio of $>40 \%$ ) (Figure 4 ). It must be kept in mind that other diseases besides IgGrelated sclerosing disease can give rise to increased numbers of IgG4 cells in lymph nodes. In particular, the possibility of a parasitic infestation and an allergic condition should be ruled out clinically and pathologically.

\section{Reactive paracortical interfollicular hyperplasia}

Reactive paracortical/interfollicular hyperplasia is a relatively common lymph-node pattern. The process is virtually never that of reactive paracortical hyperplasia without any participation by other compartments, particularly reactive follicular hyperplasia, 
Table 4 Reactive lymphadenopathies with a predominant paracortical pattern

- Non-specific reactive paracortical hyperplasia

- Nodular paracortical T-cell hyperplasia

- Viral:

○ Epstein-Barr

- Cytomegalovirus

○ Herpesvirus

- Postvaccinial

- Drug induced

- IgG4-related sclerosing disease

- Dermatopathic lymphadenitis

but also reactive sinus hyperplasia. However, this section will consider those diseases in which reactive paracortical hyperplasia represents the dominant histologic pattern. This is important to consider from a differential diagnostic viewpoint as well as possibly suggesting a specific diagnosis.

A specific etiology cannot be determined for the large majority of cases of reactive paracortical hyperplasia. Similarly to reactive follicular hyperplasia, reactive paracortical hyperplasia occurs in all age groups, but is more common in young patients. Table 4 lists the most common diseases that give rise to histologic findings that may suggest the specific etiology of the paracortical hyperplasia.

In reactive paracortical hyperplasia, one sees expansion of the paracortical areas by a mixed infiltrate, often imparting a mottled appearance. There is usually a concomitant reactive follicular hyperplasia. At high magnification, the paracortical areas usually show a mixture of small and large lymphoid cells, but without significant cytologic atypia (the latter manifested by highly irregular or hyperchromatic nuclei). There are often immunoblasts, which are usually relatively evenly dispersed, and large numbers of plasma cells, eosinophils, and histiocytes are typical (Figure 5). Vascularity is often increased, usually with prominent high endothelial venules. Occasionally, reactive paracortical hyperplasia may take the appearance of small to large nodules of small (and sometimes irregular) T cells admixed with dendritic cells, so-called nodular paracortical T-cell hyperplasia, found in association with a wide variety of benign and malignant disorders. When associated with melanin pigment, and usually more diffuse throughout the lymph node, a diagnosis of dermatopathic lymphadenitis may be made.

\section{Atypical paracortical/interfollicular hyperplasia}

Similarly to atypical follicular hyperplasia, atypical paracortical hyperplasia is a descriptive term that describes a diagnostic dilemma rather than a specific diagnosis. The major and most important

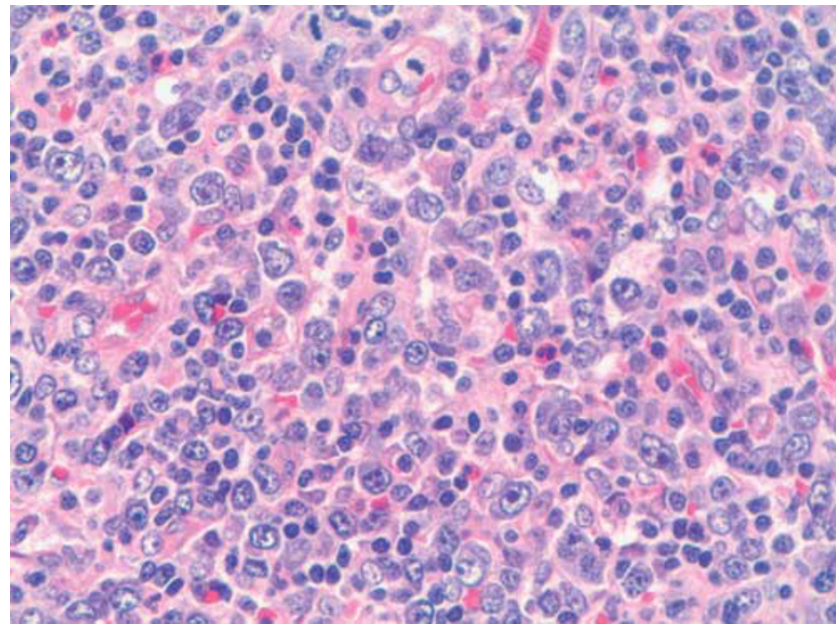

Figure 5 Reactive paracortical hyperplasia. Note the admixture of different cell types, including immunoblasts, plasma cells, histiocytes, and eosinophils.

differential diagnosis for reactive paracortical hyperplasia is peripheral T-cell lymphoma. ${ }^{17}$ Histologically, obliteration or marked diminution of the B-cell cortical region would favor a diagnosis of T-cell lymphoma, as the cortical region usually also undergoes hyperplasia in most cases of reactive paracortical hyperplasia. The most important criterion is the presence of cytologically atypical cells in T-cell lymphoma. In reactive paracortical hyperplasia, there is often an admixture of cell types, including immunoblasts, but a continuous spectrum of cytologic atypia among the lymphoid cells would favor a T-cell lymphoma. A diminution of the B-cell compartments (cortical and subcapsular areas) seen by immunohistochemical studies would favor a T-cell lymphoma. While peripheral T-cell lymphoma may contain B cells, including B immunoblasts, the greater the number of admixed $\mathrm{B}$ cells of both large and small size, the more likely the diagnosis of reactive paracortical hyperplasia. The demonstration of T-cell phenotypic abnormalities such as loss of one or more pan-T cell antigens or abnormal expression of antigens (such as loss of membrane expression of a pan-T-cell marker, of gain of CD10 or bcl-6) would favor a diagnosis of T-cell lymphoma. Finally, the molecular detection of clonal T-cell receptor gene rearrangements would provide strong evidence for a diagnosis of T-cell lymphoma.

Reactive paracortical hyperplasia and Hodgkin lymphoma may also be difficult to distinguish from one another. In the interfollicular variant of Hodgkin lymphoma, the Hodgkin cells are found in between hyperplastic follicles. Sometimes, areas that are more typical of Hodgkin lymphoma are seen elsewhere in the biopsy. Hodgkin cells tend to cluster in one area of the lymph node, are not usually associated with typical immunoblasts in a 'reactive milieu', and are usually found in their characteristic background. Careful cytologic evaluation of the large atypical cells, together with immunohistochemical 
studies seeking the typical phenotype of Hodgkin cells, should resolve most cases.

\section{Acute infectious mononucleosis}

Most initial infections with Epstein-Barr virus (EBV) occur asymptomatically in children under the age of 5 , even in western countries. Symptomatic acute infectious mononucleosis occurs in all age groups except childhood. Approximately, one-third of EBV infections occurring in adolescents is symptomatic, with a continuum of increasing percentage and severity of symptoms as initial infection occurs at older ages. The most common symptoms include sore throat, fever, and lymphadenopathy, particularly anterior or posterior cervical lymphadenopathy. However, many other lymph-node groups may be affected. Markedly enlarged tonsils are almost always present, splenomegaly is found in $50 \%$ of cases, and hepatomegaly occurs in about $10 \%$. Hematologic examination usually reveals lymphocytosis, with at least $10 \%$ atypical lymphocytes (95\% $\mathrm{T}$ cells). If the diagnosis is suspected clinically, then the diagnosis can be confirmed serologically, either by IgM monospot test or by more specific EBV antibody serologic studies. However, in cases that have come to biopsy, the diagnosis is almost always not considered clinically. Other diseases that may have a similar clinical and laboratory profile include cytomegalovirus or HHV-6 infection.

The earliest manifestation of acute infectious mononucleosis may be a prominent monocytoid B-cell proliferation, along with reactive follicular hyperplasia. However, soon after, there is an immunoblastic proliferation, which may be quite striking. ${ }^{18-20}$ These cells typically have prominent nucleoli and abundant cytoplasm. They have a high mitotic rate and may form sheets, may be

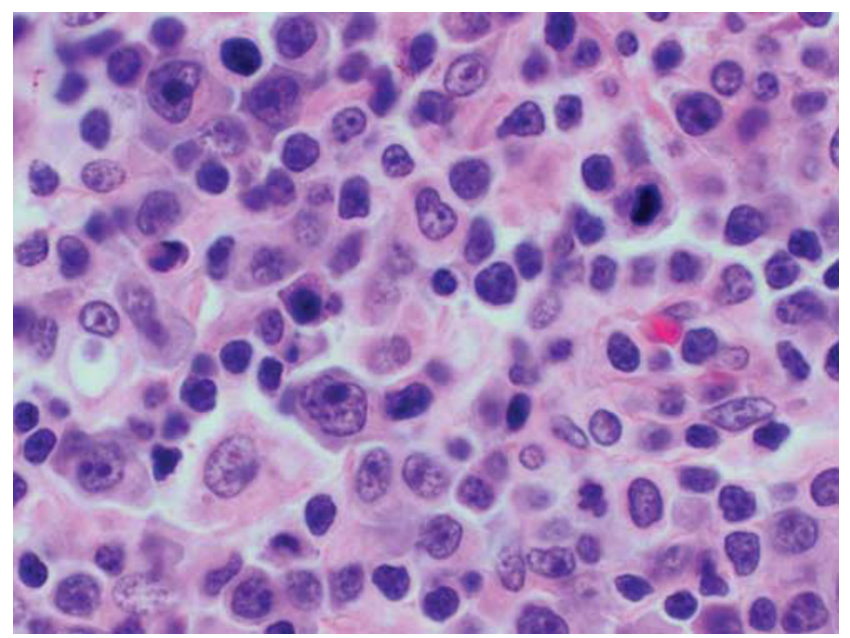

Figure 6 EBV-associated acute infectious mononucleosis. There is a mixture of cell types, including plasmacytoid cells, and individual cells with prominent nucleoli. found in sinuses, and may be multinucleated, mimicking either non-Hodgkin lymphoma or Hodgkin lymphoma (Figure 6). There are usually abundant plasma cells, and there may be eosinophils or epithelioid histiocytes. Necrosis may be absent, focal or extensive. Follicles usually show striking reactive follicular hyperplasia, but this feature may be overshadowed by the paracortical hyperplasia.

Immunohistochemical studies are non-specific. The monocytoid cells in the sinuses mark as B cells, the reactive germinal centers are bcl-2 negative, and the immunoblasts are a mixture of $\mathrm{T}$ and $\mathrm{B}$ cells. One may see co-expression of CD43 and CD20 on the immunoblasts, a finding that does not equate to a diagnosis of lymphoma in this setting. Many of the immunoblasts may be CD30+, including sheets of cells, a finding that does not equate to a diagnosis of anaplastic large cell lymphoma in this setting; ALK staining is negative. The most useful studies are those for identifying EBV. Virtually all cases have varying number of EBV-latent membrane protein (LMP)-positive cells, usually immunoblasts. EBV encoded RNA (EBER) in situ hybridization labels many more EBV-positive cells, including numerous large and small cells in the paracortical areas, and scattered cells in the germinal centers and monocytoid B-cell areas, and is the method of choice for the identification of EBV in this setting (Figure 7). ${ }^{21}$

The differential diagnosis includes both nonHodgkin lymphoma and Hodgkin lymphoma. Misdiagnosis of acute infectious mononucleosis as Hodgkin or non-Hodgkin lymphoma is a common error in lymph-node pathology. Simply stated, one should not diagnose a diffuse large cell lymphoma in either the tonsil or cervical lymph nodes in a child or adolescent without first considering and ruling out a possible diagnosis of acute infectious mononucleosis! In situ hybridization using EBER

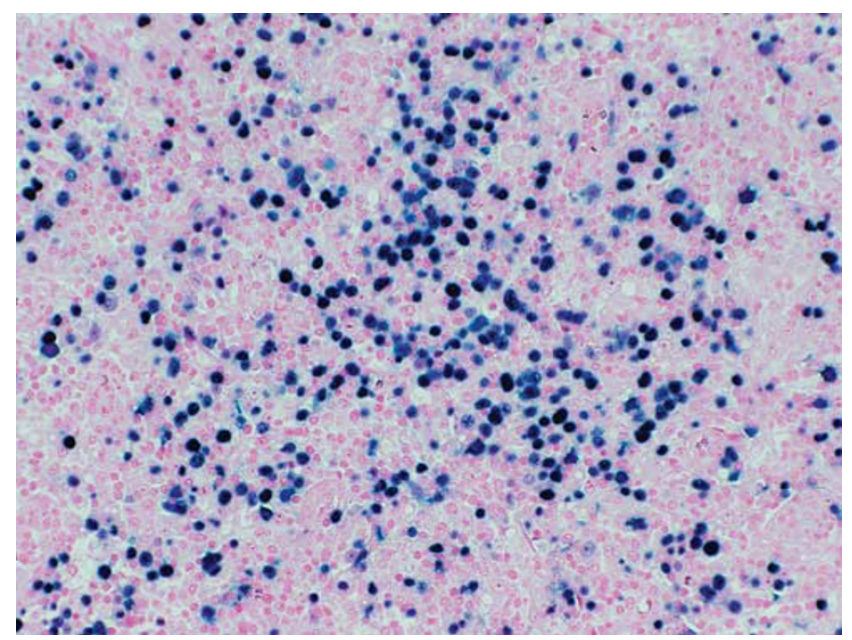

Figure 7 EBV-associated acute infectious mononcleosis, EBER stain. A characteristic mixture of small and large EBER-positive cells is seen. 
probes is the most helpful ancillary study for the tissue diagnosis of acute infectious mononucleosis. In EBV-positive diffuse large B-cell lymphomas, the EBV is uniformly present in the large neoplastic cells, and absent or virtually absent in the small lymphocytes, while in infectious mononucleosis, the positive cells are a subset of both large and small lymphocytes. Gene rearrangement studies may also be of use, however, both immunoglobulin and T-cell receptor studies may show oligoclonal or occasionally monoclonal patterns of gene rearrangement. A diagnosis of Hodgkin lymphoma may be considered if one focuses too carefully on the high magnification appearance of the immunoblasts, but the overall context is not that of Hodgkin lymphoma, with a high mitotic rate and usually an accompanying florid reactive follicular hyperplasia. In situ hybridization may show EBV positivity in classical Hodgkin lymphoma (particularly in cases occurring in patients under the age of 21), but almost all the positive cells are large cells, and there are many fewer positive cells than seen in acute infectious mononucleosis, which has both large and small positive cells. In contrast to classical Hodgkin lymphoma, immunohistochemical studies do not show CD15 reactivity in the large cells in acute infectious mononucleosis, although many large cells may express CD30 and lack CD45 expression, similarly to classical Hodgkin lymphoma.

\section{Benign lymphadenopathy with extensive necrosis}

Any benign lymphadenopathy may at times show necrosis, either focal or extensive. However, some lymphadenopathies characteristically show extensive necrosis. ${ }^{22}$

\section{Kikuchi histiocytic necrotizing lymphadenitis}

Kikuchi histiocytic necrotizing lymphadenitis is an inflammatory disorder of unknown etiology. ${ }^{23-26}$ It most commonly affects young Asian women, although it may occur in both sexes and in all age groups and ethnicities. Patients most often present with isolated cervical lymphadenopathy, which may be tender, and of several months duration. They sometimes have a history of a fever with upper respiratory symptoms; less commonly, they may have systemic symptoms, such as malaise and weight loss. The prognosis is excellent, with resolution usually occurring with 1-4 months, although some patients may relapse. No convincing association with viruses has been found, and an autoimmune pathogenesis has been proposed, given that the similar histologic appearance seen in lymph nodes involved by systemic lupus erythematosis.

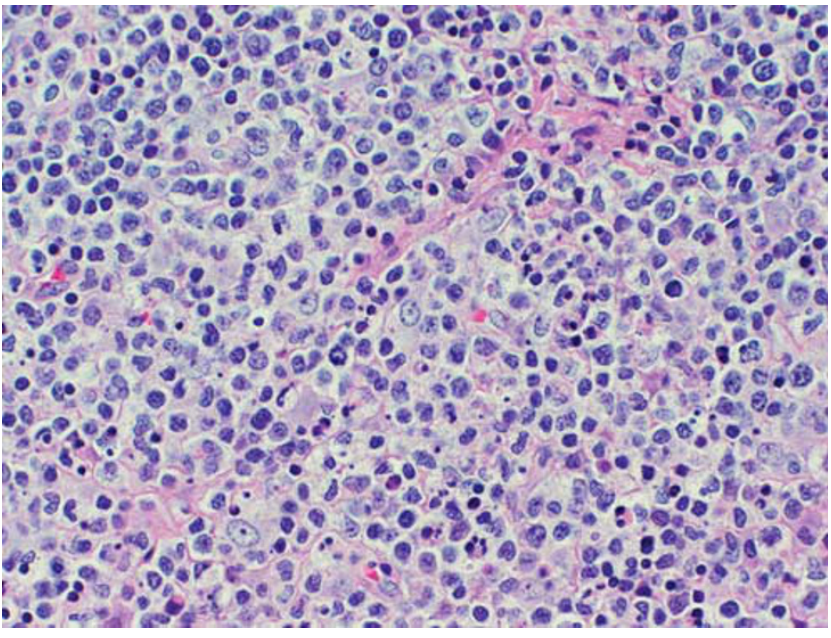

Figure 8 Kikuchi histiocytic necrotizing lymphadenitis, proliferative phase. This field, containing numerous macrophages, could be easily mistaken for a diffuse large cell lymphoma. Note the scattered karyorrhectic debris, which is a clue to the correct diagnosis.

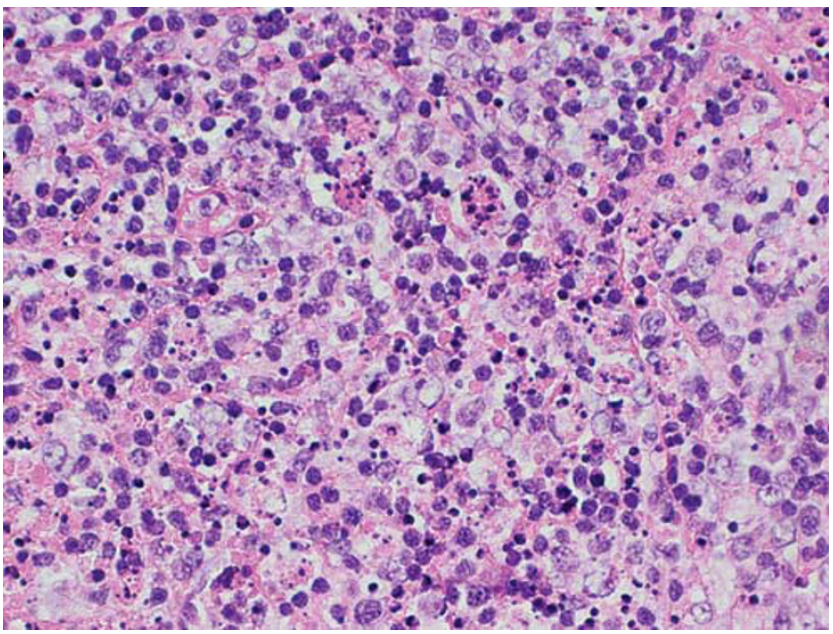

Figure 9 Kikuchi histiocytic necrotizing lymphadenitis, progressing toward the necrotic stage. There is more abundant karyorrhexis seen than in Figure 8, with the beginning of fibrin deposition.

Grossly involved lymph nodes are usually only mildly enlarged. Histologically, three phases have been described. In the first phase, the proliferative phase, there are patchy areas of involvement, with adjacent areas showing a non-stimulated appearance or a non-specific reactive follicular and/or paracortical hyperplasia. In the areas of involvement, there is a proliferation of medium-to-large lymphoid cells, histiocytes, and plasmacytoid dendritic cells (Figure 8). Scattered small lymphocytes may be present, but do not dominate the histologic picture. The histiocytes have a bland chromatin pattern, but may have highly irregular nuclear outlines (eg, crescentic, twisted, or even signet-ring shaped nuclei). They often contain phagocytosed 
cellular fragments. The plasmacytoid dendritic cells are hard to identify when present singly, but tend to cluster, particularly at the edges of the lesion. Neutrophils, eosinophils, and plasma cells are rare. There is usually no widespread necrosis at this stage, although single cell necrosis and karyorrhectic debris may be present and even prominent (Figure 9). In the second phase-the necrotic phase-focal to extensive areas of geographic necrosis are present. These areas show an eosinophilic appearance, often with admixed karyorrhectic debris. Once again, mature neutrophils are rare, and medium-to-large sized lymphoid cells and histiocytes are usually present at the margins of the necrosis. In the final phase, the resolution stage, large numbers of foamy macrophages may be seen. Immunohistochemical studies show a predominance of T cells and macrophages. Helper/inducer (CD3 + / $\mathrm{CD} 4+$ ) cells predominate in the early phase, while cytotoxic/suppressor (CD3 + /CD8 +) cells predominate in the more commonly biopsied necrotic stage. Only scattered CD20 + B immunoblasts are present. CD123 is a good marker for confirming the presence of plasmacytoid dendritic cells.

The typical clinical setting of Kikuchi necrotizing histiocytic lymphadenitis should be kept in mind in the differential diagnosis with non-Hodgkin lymphoma. The proliferative stage of the disease, in particular, may be easily mistaken for a diffuse large cell lymphoma, with its predominance of mediumto-large lymphoid cells, histiocytes, and plasmacytoid dendritic cells. The presence of abundant karyorrhectic debris should raise suspicion of necrotizing histiocytic lymphadenitis. Immunohistochemical studies showing few B cells will rule out the possibility of a B-cell lymphoma, and a predominance of CD8 + cells, if found, is only seen in a minority of cases of peripheral T-cell lymphoma. The presence of focal necrosis raises the differential diagnosis with Hodgkin lymphoma, but the absence of morphologic and immunohistologic evidence of Hodgkin cells at the border of the necrosis would make this diagnosis unlikely. Granulomatous necrotizing lymphadenitis has greater numbers of neutrophils and epithelioid histiocytes, forming stellate microabscesses as opposed to patchy areas of necrosis, while non-suppurative granulomatous inflammation usually has well (or at least better) defined granulomas, which may show central caseation. Systemic lupus erythematosis may have additional features such as scattered plasma cells and, more rarely, hematoxylin bodies in sinuses that distinguish it from Kikuchi histiocytic necrotizing lymphadenitis, but at times may have an identical histologic appearance. For this reason, appropriate serologic and other studies should always be performed in all potential cases of Kikuchi histiocytic necrotizing lymphadenitis to rule out this possibility. Finally, Kawasaki disease can be distinguished by its clinical setting and greater extent of vascular changes.

\section{Disclosure/conflict of interest}

These authors declare no conflict of interest.

\section{References}

1 Moore S, Schneider J, Schaaf H. Diagnostic aspects of cervical lymphadenopathy in children in the developing world: a study of 1,877 surgical specimens. Pediatr Surg Int 2003;19:240-244.

2 Dorfman RF, Warnke RA. Lymphadenopathy simulating the malignant lymphomas. Hum Pathol 1974;5: 519-550.

3 Segal GH, Perkins SL, Kjeldsberg CR. Benign lymphadenopathies in children and adolescents. Semin Diagn Pathol 1995;12:288-302.

4 Osborne BM, Butler JJ. Clinical implications of nodal reactive follicular hyperplasia in elderly patients with enlarged lymph nodes. Mod Pathol 1991;4:24-30.

5 Nathwani BN, Winberg CD, Diamond LW, et al. Morphologic criteria for the differentiation of follicular lymphoma from florid reactive follicular hyperplasia: a study of 80 cases. Cancer 1981;48:1794-1806.

6 Good DJ, Gascoyne RD. Atypical lymphoid hyperplasia mimicking lymphoma. Hematol Oncol Clin North Am 2009;4:729-745.

7 Lai R, Arber DA, Chang KL, et al. Frequency of bcl-2 expression in non-Hodgkin's lymphoma. A study of 798 cases with comparison of marginal zone lymphoma and monocytoid B cell hyperplasia. Mod Pathol 1998;11:864-869.

8 Wood BL, Bacchi MM, Bacchi CE, et al. Immunocytochemical differentiation of reactive hyperplasia from follicular lymphoma using monoclonal antibodies to cell surface and proliferation-related markers. Appl Immunohistochem 1994;2:48-53.

9 Weiss LM, Loera S, Bacchi CE. Immuoglobulin light chain immunohistochemistry revisited, with emphasis on reactive follicular hyperplasia versus follicular lymphoma. Appl Immunohistochem Mol Morphol 2010;18:199-205.

10 Nam-Cha SH, San-Millan B, Mollejo M, et al. Lightchain-restricted germinal centres in reactive lymphadenitis: report of eight cases. Histopatology 2008;52: 436-444.

11 Kussick SJ, Kalnoski M, Braziel RM, et al. Prominent clonal B-cell populations identified by flow cytometry in histologically reactive lymphoid proliferations. Am J Clin Pathol 2004;121:464-472.

12 Segal GH, Scott M, Jorgensen T, et al. Standard polymerase chain reaction analysis does not detect $\mathrm{t}(14 ; 18)$ in reactive lymphoid hyperplasia. Arch Pathol Lab Med 1994;118:791-794.

13 Sevilla DW, Murty W, Sun XL, et al. Cytogenetic abnormalities in reactive lymphoid hyperplasia: byproducts of the germinal center reaction or indicators of lymphoma? Hematol Oncol 2011;29:81-20.

14 Cheuk W, Yuen HK, Chu SY, et al. Lymphadenopathy of IgG4-related sclerosing disease. Am J Surg Pathol 2008;32:671-681.

15 Grimm KE, Barry TS, Chizhevsky V, et al. HIstopathological findings in 29 lymph node biopsies with increased IgG4 plasma cells. Mod Pathol 2012;25:480-491.

16 Cheuk W, Chan JK. IgG4-related sclerosing disease: a critical apprasial of an evolving clinopathologic entity. Adv Anat Pathol 2010;17:303-332. 
17 Kojima M, Nakamura S, Itoh $\mathrm{H}$, et al. Acute viral lymphadenitis mimicking low-grade peripheral T-cell lymphoma. A clinicopathological study of nine cases. APMIS 2001;109:419-427.

18 Childs CC, Parham DM, Berard CW. Infectious mononucleosis. The spectrum of morphologic changes simulating lymphoma in lymph nodes and tonsils. Am J Surg Pathol 1987;11:122-132.

19 Shin SS, Berry GJ, Weiss LM. Infectious mononucleosis: diagnosis by in situ hybridization in two cases with atypical features. Am J Surg Pathol 1991;15:625-631.

20 Strickler JG, Fedeli F, Horwitz CA, et al. Infectious mononucleosis in lymphoid tissue. Histopathology, in situ hybridization, and differential diagnosis. Arch Pathol Lab Med 1993;117:269-278.

21 Weiss LM, Movahed LA. In situ demonstration of Epstein-Barr viral genomes in viral-associated
B cell lymphoproliferations. Am J Pathol 1989;134: 651-659.

22 Strickler JG, Warnke RA, Weiss LM. Necrosis in lymph nodes. Pathol Annu 1987;(Part 2):22:253-282.

23 Dorfman RF, Berry GJ. Kikuchi's histiocytic necrotizing lymphadenitis: an analysis of 108 cases with emphasis on differential diagnosis. Semin Diagn Pathol 1988;5: 329-345.

24 Hutchison CB, Wang E. Kikuchi-Fujimoto disease. Arch Pathol Lab Med 2010;134:289-293.

25 Fujimoto Y, Kozima Y, Yamaguchi K. Cervical subacute necrotizing lymphadenitis. A new clinicopathologic entity. Naika 1972;20:920-927.

26 Pileri S, Kikuchi M, Helbron D, et al. Histiocytic necrotizing lymphadenitis without granulocytic infiltration. Virchows Arch A Pathol Anat Histol 1982;395: 257-271. 